\title{
Voltage-Dependent Calcium Channels Regulate Melatonin Output from Cultured Chick Pineal Cells
}

\author{
Neil L. Harrison ${ }^{1}$ and Martin Zatz ${ }^{2}$ \\ 'Laboratory of Neurophysiology, NINCDS, National Institutes of Health, and 'Laboratory of Cell Biology, National Institute \\ of Mental Health, Bethesda, Maryland 20892
}

\begin{abstract}
Chick pineal cells maintained in primary culture display a circadian rhythm of melatonin production and release, and the nocturnal increase in melatonin output is enhanced by elevating extracellular $\mathrm{K}+$. The divalent cations, $\mathrm{Co}^{2+}, \mathrm{Cd}^{2+}$, and $\mathrm{Mn}^{2+}$, each reduce nocturnal melatonin output. Nitrendipine and nifedipine also prevent the nocturnal rise in melatonin output, while Bay K 8644 increases it, suggesting a role for voltage-dependent $\mathrm{Ca}^{2+}$ channels in regulating melatonin output. The whole-cell patch-clamp technique was used to record from individual chick pineal cells. Under conditions designed to isolate currents through voltage-dependent $\mathrm{Ca}^{2+}$ channels, biphasic inward currents are elicited by large depolarizing commands (e.g., to $0 \mathrm{mV}$ ) from a holding potential of $-90 \mathrm{mV}$; from a holding potential of $-40 \mathrm{mV}$, only a sustained inward current is elicited by steps to $0 \mathrm{mV}$. Both components of the inward current are blocked by $\mathrm{Co}^{2+}$ or $\mathrm{Cd}^{2+}$. The sustained current is increased in amplitude by Bay K 8644 and blocked by nifedipine, while the transient current is unaffected. Since there is no evidence for vesicular release of melatonin, the "L-type" calcium channels mediating the sustained calcium current appear to be involved in the pathways regulating melatonin synthesis in chick pineal cells.
\end{abstract}

The avian and mammalian pineal glands each display a circadian rhythm of melatonin production, synthesizing and releasing melatonin at night in vivo (Takahashi and Zatz, 1982). The rat pineal does not spontaneously produce melatonin. It synthesizes and releases melatonin in response to the cycle of adrenergic stimulation imposed by its sympathetic innervation. Melatonin synthesis is induced by $\beta$ - and $\alpha_{1}$-adrenergic receptor stimulation (Klein, 1985). In contrast, the chick pineal continues to exhibit a circadian rhythm of melatonin release after removal from the animal (Deguchi, 1979a); dissociated chick pineal cells display such a rhythm in tissue culture (Robertson and Takahashi, 1988; Zatz et al., 1988). The "spontaneous" nocturnal increase in melatonin production by chick pineal cells is inhibited by light and by $\alpha_{2}$-adrenoceptor activation (Deguchi, 1979b; Pratt and Takahashi, 1987; Voisin et al., 1987; Zatz and Mullen, 1988a).

\footnotetext{
Received July 18, 1988; revised Dec. 12, 1988; accepted Jan. 9, 1989.

We thank Deborah Mullen for skilled technical assistance, Nevin Lambert for his participation in a few of the experiments, and Dr. Jeffery L. Barker for his support of this work.

Correspondence should be addressed to Dr. N. L. Harrison, Department of Anesthesia and Critical Care, The University of Chicago, Chicago, IL 60637.

0270-6474/89/072462-06\$02.00/0
}

The nocturnal rise in melatonin production by cultured chick pineal cells is enhanced by bathing the cells in elevated external $\mathrm{K}^{+}$(Zatz et al., 1988). Since melatonin readily crosses cell membranes, and there is no evidence for storage or exocytotic release (Zatz, 1982; Klein, 1985), this result suggests that membrane depolarization might promote melatonin synthesis. In rat pineal, the potentiating effect of $\alpha_{1}$-adrenergic stimulation requires external $\mathrm{Ca}^{2+}$ (Sugden et al., 1986, 1987). This observation led us to investigate the possibility that $\mathrm{Ca}^{2+}$ entry might regulate melatonin output from chick pineal cells.

Calcium ions play important roles in regulating a wide variety of cellular functions. Increases in intracellular ionized calcium levels $\left(\left[\mathrm{Ca}^{2+}\right]_{i}\right)$ trigger changes in secretion and synthesis in endocrine cells of many types; such increases in $\left[\mathrm{Ca}^{2+}\right]_{i}$ often arise as a consequence of $\mathrm{Ca}^{2+}$ entry through voltage-dependent calcium channels (VDCC). There is pharmacological and electrophysiological evidence for the existence of at least 3 distinct classes of VDCC, e.g., in chick sensory neurons (Fox et al., 1987a, b).

We have used electrophysiological and biochemical techniques to demonstrate the existence and functional role of VDCC in chick pineal cells. Our results show that chick pineal cells possess 2 distinct calcium channel currents and that 1 of these 2 classes of VDCC, the "L-type" calcium channel, is important in regulating melatonin production and output from chick pineal cells.

\section{Materials and Methods}

Cell culture. Pineal glands were removed from 1- to 2-d-old White Leghorn chicks, and enzymatically and mechanically dissociated as previously described (Zatz et al., 1988). Pineal cell suspensions were then plated on $16 \mathrm{~mm}$ wells in 24-well plates (for melatonin release assays) or on $35 \mathrm{~mm}$ culture dishes (for electrophysiological recording). They were maintained under a cycle of $12 \mathrm{hr}$ white light and $12 \mathrm{hr}$ red light (LR 12:12) for 1-3 d (electrophysiology experiments) or 5-6 d (melatonin experiments). In this schedule, $L$ acts as "day" and $R$ acts as "night." Media from groups of 4 wells were collected for assay of melatonin shortly after onset of $\mathrm{L}$ and shortly before onset of $\mathrm{R}$.

Melatonin output assay. Cells were exposed to ${ }^{14} \mathrm{C}$-tryptophan (the precursor of melatonin) for at least $24 \mathrm{hr}$ before the start of timed collections. Media were collected into polypropylene test tubes containing $0.05 \mathrm{ml}$ of an indole carrier mix, extracted into chloroform, and backwashed with acid and base as described previously (Zatz et al., 1988). Some $3 \mathrm{ml}$ of the final chloroform phase containing ${ }^{14} \mathrm{C}$-melatonin were transferred to scintillation vials, dried, and counted. Melatonin output experiments were usually carried out in $15 \mathrm{~mm}$ external $\left[\mathrm{K}^{+}\right]$, since this condition increased the melatonin output and signal to noise in the assay. Cell density varied somewhat between different experiments, and hence control melatonin output values also varied between experiments. Each data point represents the mean \pm SEM of 4 measurements. Assay validation, and the effects of feeding schedule, media, sera, and external $\left[\mathrm{K}^{+}\right]$were described previously (Zatz et al., 1988). 
Table 1. Effects of inorganic cations on nocturnal melatonin output

\begin{tabular}{lc} 
Condition & $\begin{array}{c}\text { Nocturnal melatonin output } \\
(\mathrm{dpm} / 12 \mathrm{hr} \pm \mathrm{SD})\end{array}$ \\
\hline Control & $2880 \pm 59$ \\
$+\mathrm{CuCl}_{2} 10^{-5} \mathrm{M}$ & $210 \pm 5$ \\
$+\mathrm{MnCl}_{2} 10^{-5} \mathrm{M}$ & $1210 \pm 12$ \\
$+\mathrm{MnCl}_{2} 10^{-4} \mathrm{M}$ & $600 \pm 23$ \\
$+\mathrm{CoCl}_{2} 10^{-5} \mathrm{M}$ & $2750 \pm 81$ \\
$+\mathrm{CoCl}_{2} 10^{-4} \mathrm{M}$ & $1650 \pm 30$ \\
Daytime control & $770 \pm 26$
\end{tabular}

Electrophysiology. Electrophysiological recordings were made in white light at $22^{\circ} \mathrm{C}$ from chick pineal cells after $1-3 \mathrm{~d}$ in culture. The cells were $10-15 \mu \mathrm{m}$ in diameter, and approximately spherical in appearance under phase-contrast optics; only an occasional single process was observed. The whole-cell patch-clamp technique (Hamill et al., 1981) was used. Patch pipettes were pulled on a microprocessor-controlled pipette puller (BB-CH; Mecanex, Basel, Switzerland) using $1.5 \mathrm{~mm}$ o.d. thinwall capillary glass (WPI Ltd., New Haven, CT). Pipette-to-bath resistances were between 4 and $7 \mathrm{M} \Omega$, and seal resistances were always in excess of $5 \mathrm{G} \Omega$ (usually $>20 \mathrm{G} \Omega$ ). Following seal formation and prior to establishing a whole-cell recording, electrode capacitance was neutralized using the capacitance compensation circuitry of the List EPC-7 amplifier. The series resistance was between 6 and $10 \mathrm{M} \Omega$, and the uncompensated portion of this was $\leq 5 \mathrm{M} \Omega$, which was negligible in comparison with the high resistance of the cells (in the $G \Omega$ range). Liquid junction potentials between intrapipette and extracellular medium were largely negated by placing a $\mathrm{Ag} / \mathrm{AgCl}$ pellet as reference electrode in a side bath containing the intrapipette medium, and connecting the 2 compartments with a low-resistance "bridge" containing agar in extracellular saline; this arrangement enabled compensation for the small remaining liquid junction potential using the List EPC-7, and was sufficiently stable for prolonged recordings. Pipette current and voltage were filtered at half sampling rate (8-pole Bessel; Frequency Devices 902LPF, Haverhill, MA) and digitized, usually at $2 \mathrm{kHz}$, using a Data Translation analog-to-digital converter ( $12 \mathrm{bit}, \pm 5 \mathrm{~V})$, and data were stored on a PDP $11 / 23$ computer for off-line analysis. Signals were also continuously monitored on a Gould 28000 pen recorder. Preprogrammed voltage commands were delivered to the patch pipette via a Data Translation digital-to-analog converter. Most data records arc illustrated as raw records. Where possible, capacitative and leakage current was digitally subtracted by addition to the raw data of an averaged and appropriately scaled current response to a small hyperpolarizing command. Current-voltage relationships are shown throughout for leaksubtracted data only. Inadequacy of space clamp was rarely suggested; "notches" in the current records and long-lasting "tails" were observed only occasionally, and these data were discarded.

Voltage-dependent calcium currents. In order to isolate currents through voltage-dependent calcium channels, the external solution was $\mathrm{K}^{+}$free and contained (in mM) $125 \mathrm{NaCl}, 10 \mathrm{CaCl}_{2}$ (or $20 \mathrm{mM} \mathrm{BaCl}_{2}$ ), $1 \mathrm{MgCl}_{2}$, 6 D-glucose, 10 HEPES/ $\mathrm{NaOH}$ (pH 7.4). Currents measured with external $\mathrm{Ba}^{2+}$ were typically larger than with $\mathrm{Ca}^{2+}$, and for this reason, $\mathrm{Ba}^{2+}$ was usually employed as charge carrier for studies of calcium channel currents. The pipette solution contained (in mM): $110 \mathrm{~N}$-methyl D-glucamine (NMG; Ikeda et al., 1986) methanesulphonate, $10 \mathrm{NMG}$ $\mathrm{Cl}, 5 \mathrm{Cs}_{4} \mathrm{BAPTA}, 5 \mathrm{MgATP}, 20$ Tris phosphocreatine, $20 \mathrm{U} / \mathrm{ml}$ creatine kinase, 5 HEPES/CsOH (pH 7.4). BAPTA was used to maintain internal $\mathrm{Ca}^{2+}$ at extremely low levels and thus minimize calcium-dependent inactivation of calcium channels. The ATP-regenerating system of Forscher and Oxford (1985) was also used to prevent "wash-out" of calcium current during recording from these small cells (cf. Byerly and Yazejian, 1986). $\mathrm{Ba}^{2+}$ current amplitudes were small but stable for at least $20 \mathrm{~min}$ before declining irreversibly.

Chemicals. All chemicals were obtained from Sigma, with the exception of creatine kinase (Boehringer Mannheim Biochemicals), BAPTA (Molecular Probes Ltd., Junction City, OR), Bay K 8644, nitrendipine and nifedipine (Miles Laboratories). L-[side-chain-3-14 C]-tryptophan (specific activity, 52-57 $\mathrm{mCi} / \mathrm{mmol}$ ) was obtained from New England Nuclear (Boston).
Table 2. Dose-dependent effects of nitrendipine and Bay K 8644 on nocturnal melatonin output

\begin{tabular}{cccl} 
& $\begin{array}{l}\text { Nocturnal } \\
\text { melatonin } \\
\text { output } \\
\text { (dpm/12 } \\
\mathrm{hr} \pm \mathrm{SD})\end{array}$ & {$[$ Bay K 8644] } & $\begin{array}{l}\text { Nocturnal } \\
\text { melatonin } \\
\text { output } \\
\text { (dpm/12 } \\
\mathrm{hr} \pm \mathrm{SD})\end{array}$ \\
\hline 0 & $2040 \pm 80$ & 0 & $3650 \pm 200$ \\
$3 \mathrm{nM}$ & $1870 \pm 70$ & $1 \mathrm{nM}$ & $3530 \pm 96$ \\
$10 \mathrm{nM}$ & $1750 \pm 52$ & $10 \mathrm{nM}$ & $4380 \pm 194$ \\
$30 \mathrm{nM}$ & $1580 \pm 56$ & $100 \mathrm{nM}$ & $5370 \pm 295$ \\
$100 \mathrm{nM}$ & $1190 \pm 9$ & $1 \mu \mathrm{M}$ & $5450 \pm 114$ \\
Daytime control & $650 \pm 12$ & Daytime control & $1260 \pm 36$ \\
\hline
\end{tabular}

\section{Results}

\section{Melatonin output experiments}

The nocturnal increase in melatonin output from cultured chick pineal cells was blocked by addition to the medium of $\mathrm{Mn}^{2+}$, $\mathrm{Co}^{2+}$, or $\mathrm{Cd}^{2+}$ ions (Table 1). $\mathrm{Cd}^{2+}$ was more potent than $\mathrm{Mn}^{2+}$ or $\mathrm{Co}^{2+}$ in reducing nocturnal melatonin output, being effective at $10^{-5} \mathrm{M}$; the other divalent cations were effective at $10^{-4} \mathrm{M}$. The effects of $\mathrm{Mn}^{2+}$ and $\mathrm{Co}^{2+}$ were partially reversible, while the effect of $\mathrm{Cd}^{2+}$ was not.

Nitrendipine and nifedipine also prevented the nocturnal increase in melatonin output in a concentration-dependent manner (Table 2). Threshold effective concentrations of these agents were 1-3 nM. The nocturnal rise in melatonin output was completely blocked at micromolar concentrations, and the $\mathrm{IC}_{50}$ for both drugs was $\sim 50 \mathrm{~nm}$. The organic calcium channel "agonist" Bay K 8644 enhanced the nocturnal increase in melatonin production in a concentration-dependent manner (Table 2). Threshold effective concentrations of Bay K 8644 were 3-10 nM. Most melatonin release experiments were carried out in 15 mM external $\left[\mathrm{K}^{+}\right]$, as described in Materials and Methods. The maximal effects of the dihydropyridine "antagonists" at $10 \mu \mathrm{M}$ were similar to those of the metal ions, whether external $\left[\mathrm{K}^{+}\right]$ was $5 \mathrm{~mm}$ (low $\mathrm{K}$ ) or $15 \mathrm{~mm}$ (high $\mathrm{K}$ ) (Table 3 ).

\section{Biphasic calcium channel currents}

In voltage-clamped chick pineal cells, internally dialyzed with $\mathrm{K}^{+}$-free solution and externally bathed in $\mathrm{K}^{+}$-free saline containing $10 \mathrm{mM} \mathrm{Ca}^{2+}$ or $20 \mathrm{mM} \mathrm{Ba}^{2+}$, depolarizing voltage commands from hyperpolarized membrane potentials evoked small-amplitude (5-20 pA) biphasic inwardly directed membrane currents (Fig. 1a). The biphasic nature of the calcium channel current evoked from a holding potential of $-90 \mathrm{mV}$ was abolished by holding at more depolarized potentials (Fig. $1 b)$. The amplitude of the sustained calcium channel current was increased by addition of Bay K 8644 to the bathing medium

\begin{tabular}{|c|c|c|}
\hline \multirow[b]{2}{*}{ Condition } & \multicolumn{2}{|c|}{$\begin{array}{l}\text { Nocturnal melatonin output } \\
(\mathrm{dpm} / 12 \mathrm{hr} \pm \mathrm{SD})\end{array}$} \\
\hline & $5 \mathrm{mM} \mathrm{K}^{+}$ & $15 \mathrm{mM} \mathrm{K}^{+}$ \\
\hline Control & $740 \pm 15$ & $1020 \pm 36$ \\
\hline Nitrendipine, $10^{-5} \mathbf{M}$ & $220 \pm 10$ & $250 \pm 9$ \\
\hline $\mathrm{MnCl}_{2}, 10^{-4} \mathrm{M}$ & $180 \pm 11$ & $190 \pm 13$ \\
\hline Daytime control & $400 \pm 8$ & $580 \pm 13$ \\
\hline
\end{tabular}


a
Holding potential $-90 \mathrm{mV}$ Test potential $+5 \mathrm{mV}$

b

Holding potential $-40 \mathrm{mV}$
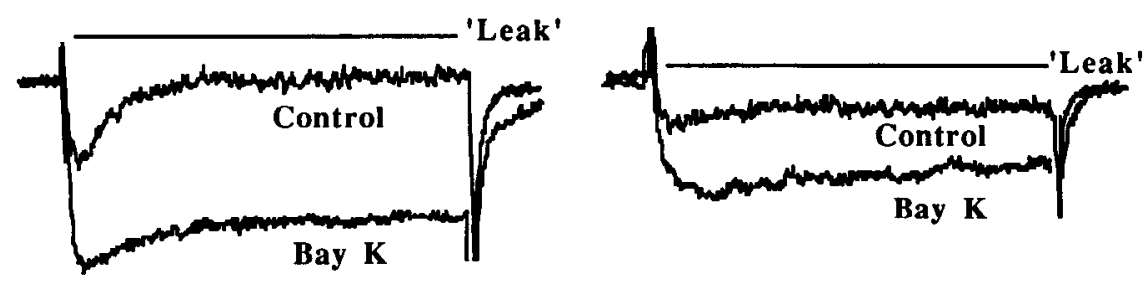

Figure 1. a, Biphasic inward $\mathrm{Ba}^{2+}$ current at a holding potential of $-90 \mathrm{mV}$ and the effect of $1 \mu \mathrm{M}$ Bay K 8644 . The line marked "leak" represents the level of membrane current that would be measured in response to the voltage step, if no active inward current was present. $b$, Inward $\mathrm{Ba}^{2+}$ current from $-40 \mathrm{mV}$ and the effect of $1 \mu \mathrm{M}$ Bay K 8644. $c$, Effect of $1 \mu \mathrm{M}$ Bay K 8644 on the leaksubtracted steady-state current-voltage relationship obtained from a holding potential of $-90 \mathrm{mV}$. Open symbols represent control data; filled symbols, data obtained in the presence of Bay $\mathrm{K}$ 8644.

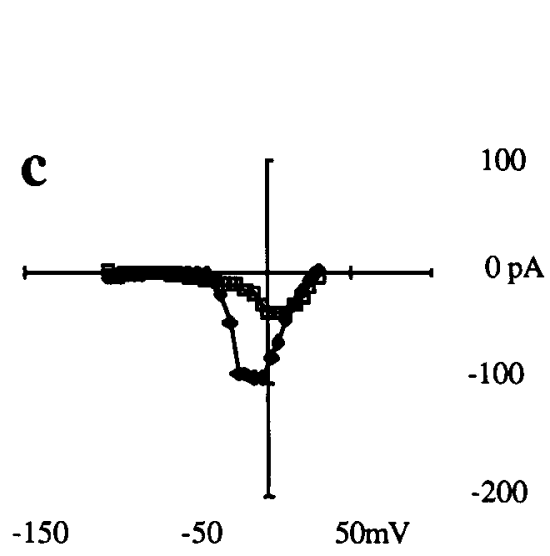

(Fig. 1a). This increase in the steady-state current amplitude by Bay K 8644 was more apparent over the negative and zero slope region of the current-voltage relation (Fig. 1c), being less obvious as inward current declined at more positive potentials.

The transient component of the inward current was unaltered by Bay $\mathrm{K} 8644$. The sustained inward current was rather small in amplitude (5-10 pA), but it was possible to demonstrate a reversible block of the current by dihydropyridines such as ni-

$\mathbf{a}$

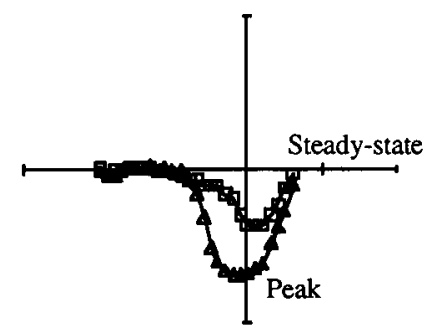

$-150$

b leak-subtracted current-voltage relationships for peak inward current and steady-state current. The triangles represent the peak currents, and the squares represent the steady-state currents. At a holding potential of -90 $\mathrm{mV}$, peak and steady-state curves are clearly different, while at a holding potential of $-40 \mathrm{mV}$, they are indistinguishable. $b$, Effect of $5 \mathrm{mM} \mathrm{Co}^{2+}$ on the leak-subtracted current-voltage relationships. Both components of inward current are abolished in the presence of $5 \mathrm{~mm} \mathrm{Co}{ }^{2+}$. Open triangles represent control peak currents; open squares, control steady-state currents; filled symbols, currents in the presence of 5 $\mathrm{mM} \mathrm{Co}{ }^{2+}$
$50 \mathrm{mV}$
Holding potential $=-90 \mathrm{mV}$

Holding potential $=-40 \mathrm{mV}$

$-50$

$50 \mathrm{mV}$

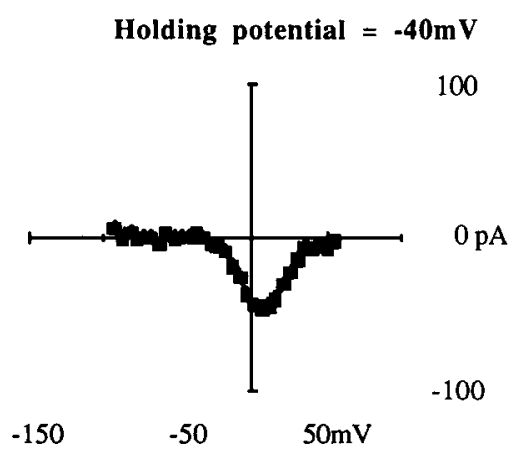

Peak currents

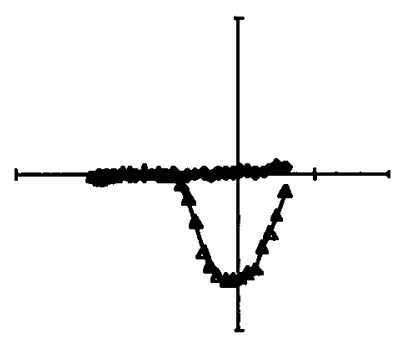

$-150$
Steady-state currents

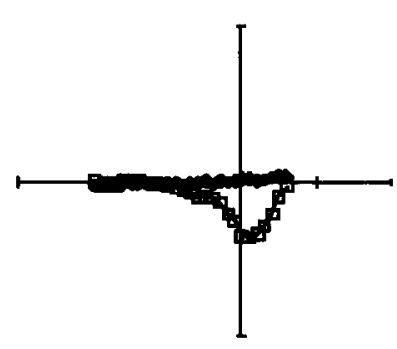

100

$0 \mathrm{pA}$ 
$\mathbf{a}$
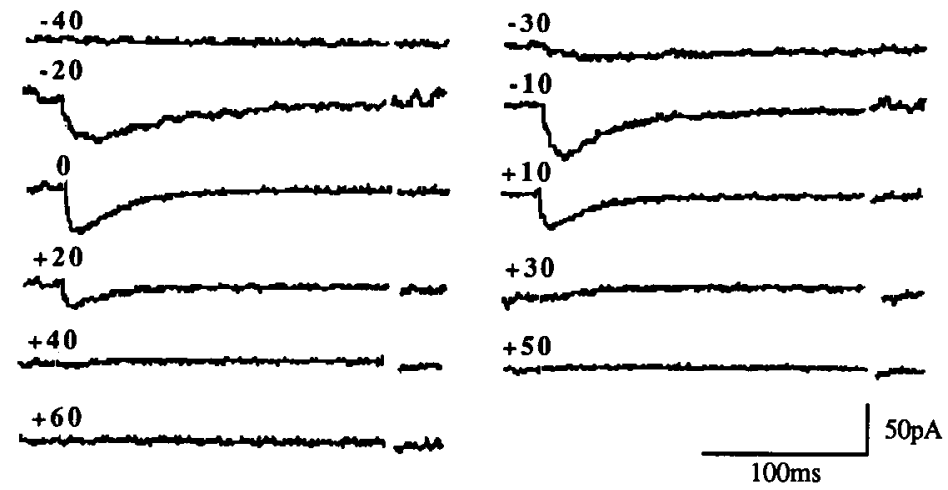

b

c
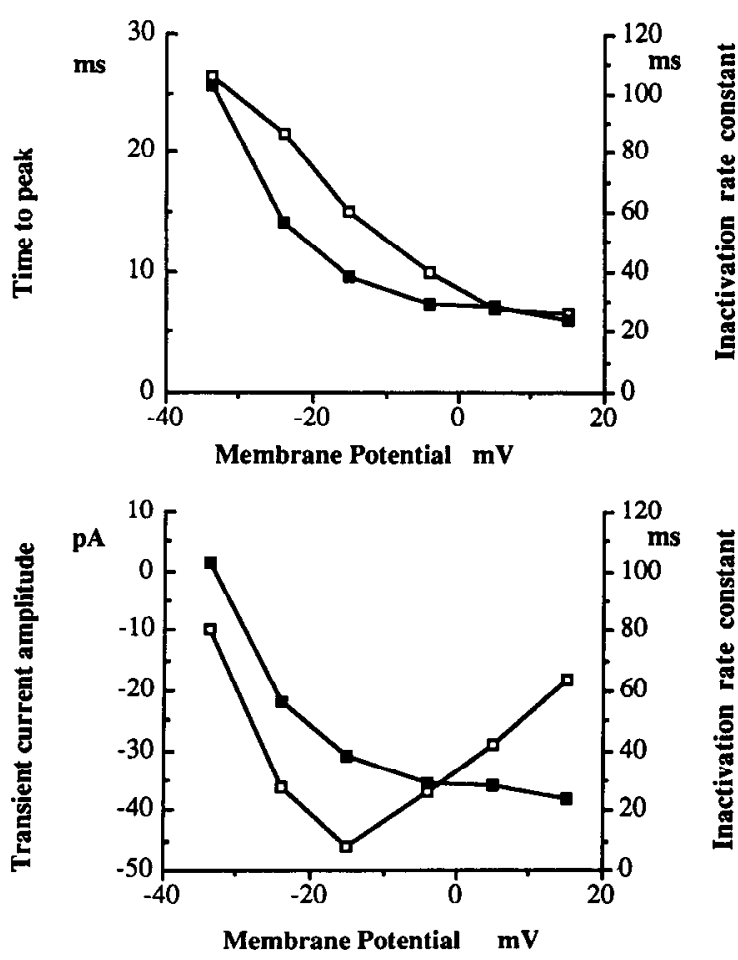

Figure 3. a, Inactivation of the transient current at various test potentials in a cell with little sustained current. $b$, Effect of membrane potential on the activation and inactivation kinetics of the transient current. Open symbols represent time to peak for the transient current, and filled symbols represent the inactivation rate constants. Both activation and inactivation are accelerated by membrane depolarization. $c$, Relationship between membrane potential and both inactivation rate and transient current amplitude. Open symbols represent the amplitude of the transient current, and filled symbols represent the inactivation rate constants. It is apparent that the amplitude of the transient current is unrelated to the inactivation rate, whereas inactivation is progressively faster as membrane potential becomes more depolarized. trendipine. In addition, if the sustained current was already enhanced in amplitude by addition of Bay $\mathrm{K} 8644$, the subsequent addition of nifedipine following Bay K 8644 restored the current to near control levels. The sustained inward current was also blocked by application of low concentrations (10-20 $\mu \mathrm{M})$ of $\mathrm{Cd}^{2+}$.

Leak-subtracted current-voltage relationships constructed at -90 and $-40 \mathrm{mV}$ show a clear difference between peak inward current and "steady-state" inward current at $-90 \mathrm{mV}$ but not at $-40 \mathrm{mV}$ (Fig. 2a), indicating the likelihood that a transient component of inward current is activated by steps from -90 $\mathrm{mV}$ that is not present when depolarizing steps are made from $-40 \mathrm{mV}$. From a holding potential of $-90 \mathrm{mV}$, both the transient current and sustained current were evoked at similar test potentials, usually at -40 to $-30 \mathrm{mV}$. Both transient and sustained components of the inward current werc abolished by $2-5$ mM Co ${ }^{2+}$ (Fig. $2 b$ ) or $200 \mu \mathrm{M} \mathrm{Cd}{ }^{2+}$.

\section{Voltage-dependent inactivation of transient current}

Using a range of holding potentials between -90 and $-30 \mathrm{mV}$, the steady-state inactivation of the transient component of calcium channel current was examined. In $20 \mathrm{~mm}$ external $\mathrm{Ba}^{2+}$, inactivation was first detectable at $-70 \mathrm{mV}$, with complete inactivation obtained at $-30 \mathrm{mV}$. Fifty percent inactivation occurred at a holding potential of $-55 \mathrm{mV}$.

In one cell in which little of the sustained component of $\mathrm{Ca}^{2+}$ channel current was detectable, the kinetic properties of the transient current were examined in detail by measuring activation and inactivation times for the transient current from leakand capacity-subtracted records (Fig. $3 a$ ). The rates of activation and inactivation of the transient current increased with depolarization (Fig. $3 b$ ). The inactivation time constant for the transient current was depcndent on voltage but not on peak amplitude of the transient current (Fig. 3c). 
$\mathbf{a}$

I

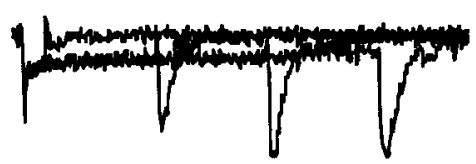

$-20$

V
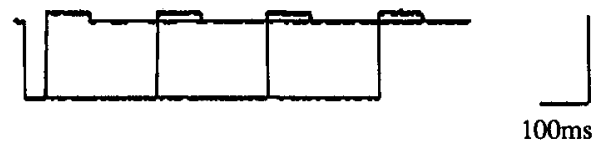

$100 \mathrm{mV}$

$50 \mathrm{pA}$ b

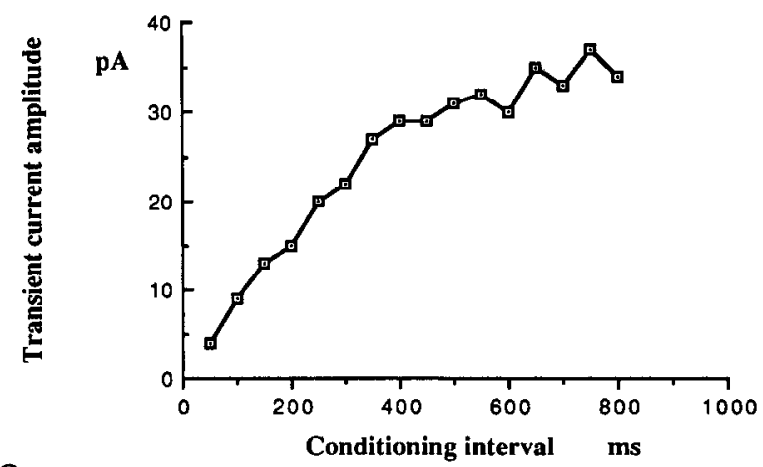

C

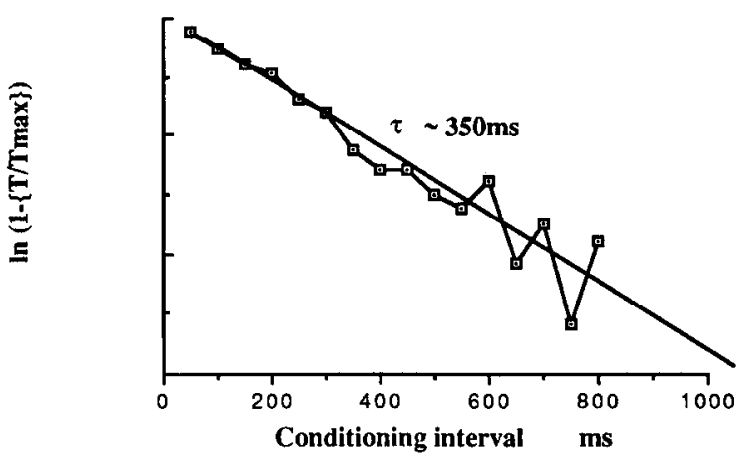

Figure 4. a, Raw records showing removal of inactivation of the transient current by hyperpolarizing steps of increasing duration from -20 to $-110 \mathrm{mV}$, followed by a test step to $-10 \mathrm{mV}$. $b$, Time-dependent recovery of the transient current from inactivation. $c$, Semilogarithmic plot of the data shown in $(b)$, together with a least-squares "best-fit" to the data, yielding a time constant of $\sim 350 \mathrm{msec}$ at $-110 \mathrm{mV}$ for the removal of inactivation of the transient current.

\section{Time-dependent removal of inactivation of transient current}

Inactivation of the transient calcium channel current was slowly removed by a conditioning hyperpolarization to $-110 \mathrm{mV}$ (Fig. $4 a$ ). Analysis of the time course of recovery from inactivation of the transient component of the calcium channel current suggested that recovery from inactivation was an exponential process (Fig. $4 b$ ). The process of recovery from inactivation was well fitted by a single-exponential function with a time constant of 350 msec (Fig. $4 c$ ).

\section{Discussion}

Two types of voltage-dependent $\mathrm{Ca}^{2+}$ channels

There are clearly 2 components of inward current through VDCC in chick pineal cells. The sustained component of inward current is increased by Bay $\mathrm{K} 8644$, a dihydropyridine that increases current flow through "L type" $\mathrm{Ca}^{2+}$ channels by altering the mode of channel gating in such a way as to promote longer duration channel openings (Hess et al., 1984). In addition, the sustained current is reduced by nifedipine and nitrendipine. This pharmacological profile suggests that the sustained current is due to $\mathrm{Ca}^{2+} / \mathrm{Ba}^{2+}$ flux through channels similar to the " $\mathrm{L}$ type" $\mathrm{Ca}^{2+}$ channels described in other preparations.

The inactivating component of $\mathrm{Ca}$ channel current has kinetic properties similar to those of the "T-type" $\mathrm{Ca}^{2+}$ channel current (low-voltage activated; Carbone and Lux, 1984) described in other preparations. The inactivation time constant for the transient component is rather voltage-sensitive, as expected for a "T-type" current (Fox et al., 1987a), and the relatively depolarized activation range of the current (more depolarized than $-40 \mathrm{mV}$ ) is not unexpected in view of the increased screening of surface charge in $20 \mathrm{~mm} \mathrm{Ba}{ }^{2+}$.

\section{Role of calcium channels in regulating melatonin output}

The nocturnal increase in melatonin output is prevented by addition to the medium of both inorganic and organic calcium channel blockers, suggesting a role for $\mathrm{Ca}^{21}$ entry in the regulation of melatonin output. The action of the metal ions $\mathrm{Co}^{2+}$, $\mathrm{Mn}^{2+}$, and $\mathrm{Cd}^{2+}$ on melatonin output may be due to blockade of $\mathrm{Ca}^{2+}$ channels by these ions. "L-type" $\mathrm{Ca}^{2+}$ channels in particular are quite sensitive to blockade by $\mathrm{Cd}^{2+}$ (Fox et al., 1987a). However, considerable caution should be exercised in interpreting the results of such experiments as these, since there is evidence from several sources that these divalent ions gain access to the cell cytoplasm (Connor et al., 1987; Hinkle et al., 1987), where they are capable of influencing a number of intracellular enzymes or inducing cytotoxicity. The possibility that the effects of these ions on melatonin output are not merely mediated via VDCC is particularly strong in the case of $\mathrm{Cd}^{2+}$. The depressant effect on melatonin output of acute application of $\mathrm{Cd}^{2+}$ was irreversible, strongly suggesting a toxic action of $\mathrm{Cd}^{2+}$ on the chick pineal cell. Although the effects of $\mathrm{Co}^{2+}$ and $\mathrm{Mn}^{2+}$ were at least partially reversible, block of melatonin output by these agents alone is not sufficient evidence to specifically implicate $\mathrm{Ca}^{2+}$ entry in the regulation of melatonin output.

The dihydropyridines, nifedipine and nitrendipine, are relatively specific agents that have been previously demonstrated to bind to and modulate the activity of one class of $\mathrm{Ca}^{2+}$ channels, the "L-type" $\mathrm{Ca}^{2+}$ channels. These agents produced a significant depression of melatonin output at submicromolar concentrations. Increasing doses of the dihydropyridines reduced melatonin output further, and a sufficient dose reduced nocturnal melatonin output below daytime levels. In addition, the $\mathrm{Ca}^{2+}$ channel "agonist" Bay K 8644, an agent that enhances $\mathrm{Ca}^{2+}$ flux through "L-type" channels, increases nocturnal melatonin output in a dose-dependent manner. Taken together with the data for the divalent cations, these observations strongly implicate $\mathrm{Ca}^{2+}$ entry through L-type $\mathrm{Ca}^{2+}$ channels in regulating melatonin output from chick pineal cells. In view of these results, it seems likely that the increase in melatonin output seen with elevated $\mathrm{K}^{+}$results from an increase in $\mathrm{Ca}^{2+}$ entry through L-type $\mathrm{Ca}^{2+}$ channels as a consequence of membrane depolarization.

\section{Prospects for studying phototransduction}

The chick pineal cell apparently contains all the necessary apparatus for phototransduction. The ability to make electrophysiological recordings from chick pineal cells should facilitate 
investigation of the membrane events underlying phototransduction in these cells. In the present experiments, no attempt was made to assess the effects of light or circadian rhythmicity on the distribution or function of the conductance mechanisms examined.

The experiments performed here provide evidence for an important role of $\mathrm{Ca}^{2+}$ entry through "L-type" VDCC in the pathway for melatonin output from the chick pineal cell. In addition, the electrophysiological recordings directly demonstrate the existence of VDCC in the plasma membrane of the chick pineal cell. These observations should be useful in future evaluation (Zatz and Mullen, 1988b; Zatz, 1989) of the importance of membrane potential and ion channels in regulating the output of melatonin and its circadian rhythmicity.

\section{References}

Byerly, L. P., and B. Yazejian (1986) Intracellular factors for the maintenance of calcium currents in perfused neurones from the snail, $\mathrm{Lym}$ naea stagnalis. J. Physiol. (Lond.) 370: 631-650.

Carbonc, E., and H. D. Lux (1984) Kinetics and selectivity of a low voltage-activated calcium current in chick and rat sensory neurones. Biophys. J. 46: 413-418.

Connor, J. A., H.-Y. Tseng, and P. E. Hockberger (1987) Depolarization- and transmitter-induced changes in intracellular $\mathrm{Ca}^{2+}$ of rat cerebellar granule cells in explant cultures. J. Neurosci. 7: 1384-1400.

Deguchi, T. (1979a) A circadian oscillator in cultured cells of chicken pineal gland. Nature 282: 94-96.

Deguchi, T. (1979b) Rhodopsin-like photosensitivity of isolated chicken pineal gland. Nature 290: 706-707. pineal gland. Nature 290: 706-707.

Forscher, P., and G. S. Oxford (1985) Modulation of calcium channels by norepinephrine in internally dialyzed avian sensory neurons. J. Gen. Physiol. 85: 743-763.

Fox, A. P., M. C. Nowycky, and R. W. Tsien (1987a) Kinetic and pharmacological properties distinguishing three types of calcium currents in chick sensory neurones. J. Physiol. (Lond.) 394: 149-172.

Fox, A. P., M. C. Nowycky, and R. W. Tsien (1987b) Single-channel recordings of three types of calcium channels in chick sensory neurones. J. Physiol. (Lond.) 394: 173-200.

Hamill, O. P., A. Marty, E. Neher, B. Sakmann, and F. J. Sigworth (1981) Improved patch clamp techniques for high resolution current recordings from cells and cell-free membranes. Pfluegers Arch. 391 . $85-100$.

Hess, P., J. B. Lansman, and R. W. Tsien (1984) Different modes of Ca channel gating behaviour favoured by dihydropyridine $\mathrm{Ca}$ agonists and antagonists. Nature $311: 538-544$.
Hinkle, P. M., P. A. Kinsella, and K. C. Osterhoudt (1987) Cadmium uptake and toxicity via voltage-sensitive calcium channels. J. Biol. Chem. 262: 16333-16337.

Ikeda, S. R., G. G. Schofield, and F. F. Weight (1986) $\mathrm{Na}$ and $\mathrm{Ca}^{21}$ currents of acutely isolated adult rat nodose ganglion cells. J. Neurophysiol. 55: 527-539.

Klein, D. C. (1985) Photoneural regulation of the mammalian pineal gland. In Photoperiodism, Melatonin and the Pineal Gland. D. Evered and S. Clark, eds., pp. 38-56, Ciba Foundation Symposium 117 Pitman, London.

Pratt, B. L., and J. S. Takahashi (1987) Alpha-2 adrenergic regulation of melatonin release in chick pineal cell cultures. J. Neurosci. 7:36653674.

Robertson, L., and J. S. Takahashi (1988) Circadian clock in cell culture: I. Oscillation of melatonin release from dissociated chick pineal cells in flow-through microcarrier culture. J. Neurosci. $8: 12$ 21.

Sugden, A. L., D. Sugden, and D. S. Klein (1986) Essential role of calcium influx in the adrenergic regulation of cAMP and cGMP in rat pinealocytes. J. Biol. Chem. 261: 11608-11612.

Sugden, A. L., D. Sugden, and D. S. Klein (1987) $\alpha_{1}$-Adrenoceptor activation elevates cytosolic calcium in rat pinealocytes by increasing net influx. J. Biol. Chem. 262: 741-745.

Takahashi, J. S., and M. Zatz (1982) Regulation of circadian rhythmicity. Science 217: 1104-1111.

Voisin, P., C. Martin, and J.-P. Collin (1987) $\alpha_{2}$-Adrenergic regulation of arylakylamine $\mathrm{N}$-acetyltransferase in organ-cultured chick pineal gland: Characterization with agonists and modulation of experimentally stimulated enzyme activity. J. Neurochem. 49: 1421-1426.

Zatz, M. (1982) The role of cyclic nucleotides in the pineal gland. In Cyclic nucleotides. II: Physiology and Pharmacology, J. W. Kebabian and J. A. Nathanson, eds., pp. 691-710, Springer-Verlag, New York. and J. A. Nathanson, eds., pp. 691-710, Springer-Verlag, New York.

Zatz, M. (1989) Relationship between light, calcium influx and cAMP on the acute regulation of melatonin production by cultured chick pineal cells. Brain Res. 477: 14-18.

Zatz, M., and D. A. Mullen (1988a) Norepinephrine, acting via adenylate cyclase, inhibits melatonin output but does not phase-shift the pacemaker in cultured chick pineal cells. Brain Res. 450:137-143.

Zatz, M., and D. A. Mullen (1988b) Does calcium influx regulate melatonin production through the circadian pacemaker in chick pineal cells? Effects of nitrendipine, Bay $\mathrm{K} 8644, \mathrm{Co}^{2+}, \mathrm{Mn}^{2+}$ and low extracellular $\mathrm{Ca}^{2+}$. Brain Res. 463: 305-316.

Zatz, M., D. A. Mullen, and J. R. Moskal (1988) Photoendocrine transduction in cultured chick pineal cells: Effect of light, dark and potassium on the melatonin rhythm. Brain Res. 438: 199-215. 